\title{
Co-author and co-cited reference network analysis for chlorophyll fluorescence research from 1991 to 2018
}

\author{
K. HU*, G. GOVINDJEE ${ }^{* *, a}$, J. TAN ${ }^{* * *}$, Q. XIA*, Z. DAI*, and Y. GUO ${ }^{* * * *,+}$ \\ Key Laboratory of Advanced Process Control for Light Industry, Ministry of Education, Jiangnan University, \\ Wuxi 214122, China* \\ Center of Biophysics \& Quantitative Biology, Department of Biochemistry and Department of Plant Biology, \\ University of Illinois at Urbana-Champaign, Urbana, IL 61801, USA** \\ Department of Bioengineering, University of Missouri, Columbia, MO 65211, USA ***
}

\begin{abstract}
Chlorophyll $a$ fluorescence has been extensively used in studying photosynthesis and overall physiology of plants, algae, and cyanobacteria. As a research hotspot, a large number of papers have been published. This creates a challenge for beginning researchers to gain a holistic view of co-author and co-cited reference network by reading individual publications. Further, these scientists need to understand the research trends in the field. Scientometric analysis, a method for mining publication datasets, was therefore conducted to analyze the co-author and co-cited reference network in the area of chlorophyll fluorescence research. The countries with high-citation-per-paper publications were used as filters to identify the active author communities. The representative author groupings in these representative countries were analyzed by the networkbased methods. As authors may have different active periods, their groupings are categorized to analyze their focus areas. Finally, the timeline of knowledge distribution is presented through the use of co-cited reference networks. Although our current analysis was confined to 'plant sciences', several interesting conclusions, including some caveats, are drawn in our paper to provide an overall landscape on co-author and co-cited reference network of this field.
\end{abstract}

Additional key words: Global Citation Score; JIP-test; Local Citation Score; OJIP transient; photosystem II; plant physiology; scientometrics; Web of Science.

\section{Introduction}

Chlorophyll fluorescence emission from all oxygenic photosynthetic organisms is important since it can help scientists and engineers to measure photosynthesis-related parameters rapidly and noninvasively, and to understand and influence the physiological status of plants, algae, and cyanobacteria (Papageorgiou and Govindjee 2004). For some of the earliest research on chlorophyll fluorescence in vivo, see Rabinowitch (1951, Chapter 24) and a perspective by Govindjee (1995). For a background on different aspects of chlorophylls, see Rabinowitch (1945, 1956), Scheer (1991), and Björn et al. (2009).

With rapid developments in biochemistry, biophysics, biological chemistry, molecular biology, and genetic engineering, and the increasing demand for improved photosynthesis and increased biomass production, extensive research is being done on chlorophyll fluorescence. The number of research articles, dealing with discoveries related to chlorophyll fluorescence, has been increasing dramatically. The abundance of research activities also brings difficulty for new researchers to understand the research domain holistically. Many review papers have been published by domain experts, including those on applications of chlorophyll fluorescence to photosynthesis (Guo and Tan 2015), and to remote sensing (Guanter et al. 2016, Gastellu-Etchegorry et al. 2017). Often only certain aspects are elaborated, which only reveals a partial picture of the landscape of chlorophyll fluorescence research. It is indeed difficult for researchers to gain an overall view of the field by browsing individual papers. Scientometric methods are expected to help with this need.

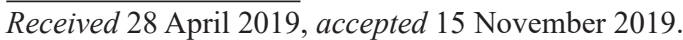

+Corresponding author; e-mail: guoy@missouri.edu, guoy@jiangnan.edu.cn

Acknowledgements: This project is partially supported by National Natural Science Foundation of China $(31771680,51961125102$, 21706096, 71904064), Fundamental Research Funds for the Central Universities of China (JUSRP51730A), the Natural Science Foundation of Jiangsu Province (BK20160162, BK20190580), the Modern Agriculture Funds of Jiangsu Province (BE2018334), the 111 Project (B12018), and the Research Funds for New Faculty of Jiangnan University. G. Govindjee was supported by the 111 Project (B12018).

aSince 2019, Govindjee (who had earlier published under one name only) is now publishing under his new formal name: Govindjee Govindjee.
} 
Scientometrics is the 'science of science'. It can be generally considered as the collection of theories and methods developed by information scientists to extract information from bibliographic datasets. Many indicators are provided by scientometric theories. The most wellknown indicators include the $\mathrm{H}$ index, and the Journal Impact Factor (JIF). These will be discussed in detail in the methodology section of this paper. Moreover, with the expansion of bibliographic datasets, scientometric analysis has become increasingly reliable in mining theories. This is done by taking a bibliographic dataset as a text content and then processing it with the techniques of nature language processing (NLP) and deep learning (Hu et al. 2018a,b). Even theories developed in statistical physics have been applied in the analysis of dynamics in the field. A wellknown example is the evaluation of the small-world effect in social network analysis (Watts and Strogatz 1998). In bibliographic datasets, a similar effect can also be detected by analyzing multiple networks of bibliographic relations, such as co-word network (Callon et al. 1991), co-citation network (Small 1973), and co-author network (Beaver and Rosen 1978).

These scientometric methods can help us visualize the domain effectively. An insight, which is very different from a traditional review paper, can be obtained by using these tools. A lot of data-driven analyses have already been conducted in some fast-growing research areas, such as food safety ( $\mathrm{Hu}$ et al. 2019), remote sensing ( $\mathrm{Hu}$ et al. 2017), transport geography (Liu and Gui 2016), and deep learning in smart agriculture (Zhu et al. 2018). These methods have helped scientists in analyzing certain focused research directions associated with certain terminology, such as Building Information Modeling (BIM) (He et al. 2017), Digital Elevation Model (DEM) (Peng et al. 2015), and Nanotechnology (Chen and Guan 2011). Recently, a bibliometric data-driven analysis for chlorophyll fluorescence research (CFR) from 1947 to 2018 was conducted by using scientometric techniques like keyword co-occurrence network, disciplinary, institution, and country collaboration network (Bąba et al. 2019). Specially, keywords and collaboration network can generally represent the knowledge distribution in different topics, disciplines, and physical spaces. The trend of the CFR was presented in a highly abstract level of core disciplinary and modern areas. However, information related to co-author and co-cited reference network analysis is necessary. Since co-author network takes the author as the node and co-cited reference network takes the cited reference as the node, they provide important details and key information on the research content, as has been done in the present paper.

The scientometric data-driven analysis in this paper emphasizes the co-author network and co-cited reference network. Our analysis is expected to help domain experts in understanding the structure of the scientific collaboration community and details of the research content through the co-cited reference network. Since research is no longer an individual effort, but a team effort, it is essential to exploit this information in choosing specific areas of research and in seeking collaboration with specific teams. Moreover, we expect the newcomers in the field to quickly grasp the most important research focus, as well as the names of most active scholars, which will enable them to quickly decide on the promising topics, trends, and the names of the key scholars to interact with.

In our work, co-author and co-cited reference network analysis for chlorophyll fluorescence research from 1991 to 2018 was conducted. Our paper is organized as follows. Under 'Data and methodology', we describe the scientometric analysis methods, and the corresponding bibliographic datasets, used in our paper. Under 'Results and analysis', we provide the structural information extracted from the bibliographic networks. Finally, under 'Discussion and conclusion', we discuss our results on chlorophyll fluorescence data, and present our concluding remarks (take-home messages), which include some caveats (such as some pitfalls that we must watch out for).

\section{Data and methodology}

Data: This analysis was conducted with datasets collected from the bibliometric database. Many bibliometric datasets are now available; these include the Web of Science (WoS) and Scopus. These two highly-recognized databases are routinely used in judging the research quality and productivity of individuals and institutions around the world. In this work, the bibliographic database used was the Core Collection database of the WoS. This database contains indexes including Science Citation IndexExpanded (SCI-Expanded) and Social Science Citation Index (SSCI), which have been most frequently used by scientists and administrators.

By searching for different topics with selected keywords, bibliographic records can be obtained. In this work, we have focused on 'chlorophyll fluorescence'. Many disciplines are related to this topic, either for studying the biological traits or for applying it for other purposes. We used 'chlorophyll fluorescence' OR 'chl $a$ fluorescence' OR 'chlorophyll $a$ fluorescence' OR 'JIP test' OR 'OJIP rise' as keywords to search the literature in the WoS dataset.

Ninety-eight WoS predefined categories (disciplines) were found in the retrieved publications. We limited our analysis to plant sciences, confining it by using search constraints. The search was confined to the WoS category of 'plant sciences', although we realize that all the categories listed are interdependent and there is much overlap. We confined the document types to 'Article(s)'. The full search constraint statement used was as follows: (TS $=$ ('chlorophyll fluorescence' OR 'Chl $a$ fluorescence' OR 'Chlorophyll $a$ fluorescence' OR 'JIP test' OR 'OJIP rise') AND $\mathrm{WC}=$ 'PLANT SCIENCES') AND LANGUAGE: (English) AND DOCUMENT TYPES: (Article), Indexes = SCI-EXPANDED, SSCI Timespan =1991-2018, where TS stands for Topics, and WC stands for WoS Categories.

The search was conducted on 28 December 2018 and included only articles published since 1991 . The retrieved datasets contain metadata information including names of authors, institutions, journals, countries, citations, and cited references. A total of 7,744 bibliographic records were obtained. With these datasets, scientometric analysis was conducted. 
Numerical methods: Although scientometrics may not be familiar to many researchers, the term Impact Factor (IF) is known to most of us; it measures the impact of a journal by computing the average number of citations for papers published in the journal. In different disciplines, the IF values may have very different meaning. Some high-IF journals are recognized by domain experts, but some lowIF journals are regarded as very classical. High-IF journals have higher citation counts since they aim to have a wider audience. This is achieved since they publish papers with much more general than specific content. On the other hand, low-IF and classical journals may have been set up for authors with very specific professional background(s); thus, they publish papers that are of interest to a small number of experts. Furthermore, the IF values are impacted by the accessibility of the journals. For example, Open Access (OA) journals are often much easier to obtain citations than traditional journals without the Open Access (OA) option, since researchers can read and cite papers published in OA journals without cost.

Although we all know that it is impossible to judge the overall quality of any research with one number such as IF, these values from scientometric data are quite popular and have been widely used in judging the quality of research as well as the work of a researcher. The $\mathrm{H}$ index is another number provided by the scientometric system (Hirsch 2005). It is used to measure an author or an institution. An $\mathrm{H}$ index value of $h$ means that an author or an organization has published at least $h$ papers, each of which had at least $h$ citations. This is easy to compute and it combines both the production and the IF in one value.

Besides the $\mathrm{H}$ index, there are other indexes that have also provided a quick overview of certain characteristics and attributes, e.g., Total Local Citation Score (TLCS), and Total Global Citation Score (TGCS). These indexes have been used in the bibliometric software HistCite ${ }^{T M}$, which was developed by Eugene Garfield (2009). Further, TLCS stands for the number of citations a paper or an author has received within a given dataset; its value is usually far lower than that of TGCS, which stands for citations received in the entire WoS database. On the other hand, TLCSx stands for citations after self-citations have been deleted from the TLCS. Thus, to some degree, TLCSx may better represent the impact of an author or a paper than TLCS in a domain. However, if someone is a major discoverer, self-citation is essential. Thus, all of these measures must be cautiously judged. Further, we note that TLCS stands for recognition from the current domain or current dataset collection, whereas TGCS for recognition from the all-science community. TGCS can help identify important domains or field of research. In summary, TLCS indicates the degree of recognition within a field and TGCS the degree of recognition from all disciplines.

Network-based methods: To understand the trend of the development in this field, the network-based methods are used. Similar to the numerical indicators like JIF (Journal Impact Factor) and the $\mathrm{H}$ index, network-based methods have had a long history. For example, the most important method in scientometrics may be the co-word network analysis (Callon et al. 1991).

However, the co-word network often misses the detailed information as to who are the active authors and how authors work in the related topics covered by the co-author network (Beaver and Rosen 1978) and the co-citation network (Small 1973). Since almost all the published papers have authors and references, the co-occurrence of them may be regarded as a co-existent relation. The co-exist relation counts one if two authors or references co-occur once in one paper and one author or reference may be linked to another author or reference in another paper. By collecting all the relationships in a bibliographic dataset, a co-author and co-cited reference network can be built. Through link reduction methods such as the Minimum Spanning Tree or the Pathfinder Network (Chen and Morris 2003), pivotal clusters or important sub-networks can be obtained. By processing obtained clusters, profound insight on the importance of a topic and a researcher can be obtained. The above discussed network-based methods were applied in the analysis presented in this paper.

\section{Results and analysis}

Academic community in terms of countries: Visualizing the co-author network is an efficient way to understand the dynamics of a research field, which is different from the traditional review work. In traditional reviews, authors often focus on the knowledge level dynamics. The relations among the knowledge levels may change from place to place and from time to time, but the co-author relations are relatively stable and profound. The co-author network reveals social interactions among the scientists and may stem from relations, such as mentor-students, teammates, international collaborators, or institute-school collaborations (Beaver and Rosen 1978, Melin and Persson 1996). Although researchers may change their topics of interest, connections among them and their previous co-authors often continue.

More frequent co-occurrences of different authors will contribute to stronger connections among the authors. The co-author network can be built to help identify the academic communities in different countries. Data on the number of records (recs), TLCS, and TLGS, from top six active countries, are shown in Table 1.

It is difficult to provide information on each research group in the world. In the following sections, we mainly describe the groups of authors from the high-averageTLCS countries list (top six). Enormous contributions have been made from scientists in countries that are not included in the top-six list. For example, India ranks at the $17^{\text {th }}$ place in the high-average-TLCS country list. In India, excellent research has been published (see e.g., Atal et al. 1991, Mishra and Singhal 1992, Djanaguiraman et al. 2005, Sherameti et al. 2008, Mehta et al. 2010). Hungary ranks at the $9^{\text {th }}$ place in the high high-average-TLCS list. From Hungary, there have been important publications (see e.g., Janda et al. 1999, Horváth et al. 2000, Hideg et al. 2002, Marschall and Proctor 2004).

We note that authors from some countries published 
smaller number of papers; however, they had a large number of in-field citations on the average (Table 1). With the countries, we first investigated the papers to see if any of the co-authors are from each of the countries. We recorded the addresses of all the authors. For example, if any author or co-author is from Switzerland, this biblio-

Table 1. Top six high-average-Total Local Citation Score (TLCS) countries. TGCS - Total Global Citation Score.

\begin{tabular}{lccrl}
\hline Country & Recs & TLCS & TGCS & Average TLCS \\
\hline Switzerland & 131 & 1,696 & 5,848 & 12.95 \\
UK & 456 & 4,845 & 21,602 & 10.63 \\
Sweden & 128 & 1,340 & 6,132 & 10.47 \\
France & 326 & 3,010 & 14,194 & 9.23 \\
USA & 1,044 & 9,249 & 44,220 & 8.86 \\
Australia & 407 & 3,563 & 16,694 & 8.75 \\
\hline
\end{tabular}

graphic dataset was counted as from Switzerland. In our study, every paper record had co-authors, and the authors were often two or more. We built the co-author network by extracting the co-authorship relations for each of the countries. With these network relationship datasets and VoSviewer (van Eck and Waltman 2010), we generated a density map. The size of an author name is proportional to the citations obtained by that author. The communities from these countries are analyzed as follows. Through computation, these authors may be identified as important authors. However, one can be classified as authors from multiple countries if his/her co-authors are from different countries. The important authors and their work in this community are shown in Table 2 .

From formed cluster in each country, we recognize that some representative authors have been co-authors with different authors in their publications (see Figs. 1-3). Fig. $1 A$ shows the co-author density map from Switzerland. By the method as used above, authors from the UK academic community (Fig. $1 B$ ) are identified and visualized

Table 2. Active authors in the academic community from Switzerland (1); UK (2); Sweden (3); France (4); USA (5); and Australia (6).

\begin{tabular}{ll}
\hline Author & Papers \\
\hline $1 \quad$ Reto Strasser & $\bullet$ A theoretical and experimental analysis of the $\mathrm{q}_{\mathrm{P}}$ and $\mathrm{q}_{\mathrm{N}}$ coefficients of chlorophyll fluorescence quenching
\end{tabular}

1 Reto Strasser - A theoretical and experimental analysis of the $\mathrm{q}_{\mathrm{p}}$ and $\mathrm{q}_{\mathrm{N}}$ coefficients of chlorophyll fluorescence quenching and their relation to photochemical and nonphotochemical events (Havaux et al. 1991)

- Probing the responses of barley cultivars (Hordeum vulgare L.) by chlorophyll a fluorescence OLKJIP under drought stress and re-watering (Oukarroum et al. 2007)

Peter Stamp - Chlorophyll fluorescence as a selection tool for cold tolerance of photosynthesis in maize (Zea mays L.) (Fracheboud et al. 1999)

- Effect of growing season on the photosynthetic apparatus and leaf antioxidative defenses in two maize genotypes of different chilling tolerance (Leipner et al. 1999)

Filippo Bussotti - Ozone symptoms in leaves of woody plants in open-top chambers: Ultrastructural and physiological characteristics (Gravano et al. 2004)

- Ozone stress in woody plants assessed with chlorophyll $a$ fluorescence. A critical reassessment of existing data (Bussotti et al. 2011)

2 Peter Horton - Molecular design of the Photosystem II light-harvesting antenna: Photosynthesis and photoprotection (Horton and Ruban 2004)

- Regulation of light-harvesting in green plants. Indication by nonphotochemical quenching of chlorophyll fluorescence (Horton et al. 1994)

Neil Baker - Imaging of photo-oxidative stress responses in leaves (Fryer et al. 2002)

- Control of Ascorbate Peroxidase 2 expression by hydrogen peroxide and leaf water status during excess light stress reveals a functional organisation of Arabidopsis leaves (Fryer et al. 2003)

Giles Johnson - The dissipation of excess excitation energy in British plant species (Johnson et al. 1993)

3 Gunner Öquist - Photoinhibition of photosynthesis represents a mechanism for long-term regulation of photosystem-II (Öquist et al. 1992)

- Seasonal changes in Photosystem II organisation and pigment composition in Pinus sylvestris (Ottander et al. 1995)

Stefan Janssen $\quad$ Lack of the light-harvesting complex CP24 affects the structure and function of the grana membranes of higher plant chloroplasts (Kovács et al. 2006)

- Antisense inhibition of the photosynthetic antenna proteins CP29 and CP26: Implications for the mechanism of protective energy dissipation (Andersson et al. 2001)

Erling Ögren • Photosynthetic light-response curves: I. The influence of $\mathrm{CO}_{2}$ partial pressure and leaf inversion (Ögren and Evans 1993)

Kjell-Öve Holmström - Improved tolerance to salinity and low temperature in transgenic tobacco producing glycine betaine (Holmström et al. 2000)

4 Michel Havaux

- Stress tolerance of Photosystem-II in vivo: Antagonistic effects of water, heat, and photoinhibition stresses (Havaux 1992)

- Characterization of thermal damage to the photosynthetic electron transport system in potato leaves (Havaux 1993) 
Daniel Epron

Gabriel Cornic

Peter Steb

Roberto Bassi (from Italy)

5 William W. Adams
- In situ estimation of net $\mathrm{CO}_{2}$ assimilation, photosynthetic electron flow and photorespiration in Turkey oak (Q. cerris L.) leaves: Diurnal cycles under different levels of water supply (Valentini et al. 1995)

- Limitation of net $\mathrm{CO}_{2}$ assimilation rate by internal resistances to $\mathrm{CO}_{2}$ transfer in the leaves of two tree species (Fagus sylvatica L. and Castanea sativa Mill.) (Epron et al. 1995)

- Partitioning of photosynthetic electron flow between $\mathrm{CO}_{2}$ and $\mathrm{O}_{2}$ reduction in a $\mathrm{C}_{3}$ leaf (Phaseolus vulgaris $\mathrm{L}$.) at different $\mathrm{CO}_{2}$ concentrations and during drought stress (Cornic and Briantais 1991)

- Limitation of net $\mathrm{CO}_{2}$ assimilation rate by internal resistances to $\mathrm{CO}_{2}$ transfer in the leaves of two tree species (Fagus sylvatica L. and Castanea sativa Mill.) (Epron et al. 1995)

- Divergent strategies of photoprotection in high-mountain plants (Streb et al. 1998)

- Evidence for alternative electron sinks to photosynthetic carbon assimilation in the high mountain plant species Ranunculus glacialis (Streb et al. 2005)

- Zeaxanthin has enhanced antioxidant capacity with respect to all other xanthophylls in Arabidopsis leaves and functions independent of binding to PSII antennae (Havaux et al. 2007)

- A mechanism of nonphotochemical energy dissipation, independent from PsbS, revealed by a conformational change in the antenna protein CP26 (Dall'Osto et al. 2005)

- Using chlorophyll fluorescence to assess the fraction of absorbed light allocated to thermal dissipation of excess excitation (Demmig-Adams et al. 1996)

- Xanthophyll cycle and light stress in nature: Uniform response to excess direct sunlight among higher plant species (Demmig-Adams and Adams 1996)

6 Wah Soon (Fred) Chow - Light inactivation of functional photosystem II in leaves of peas grown in moderate light depends on photon exposure (Park et al. 1995)

- A simple alternative approach to assessing the fate of absorbed light energy using chlorophyll fluorescence (Hendrickson et al. 2004)
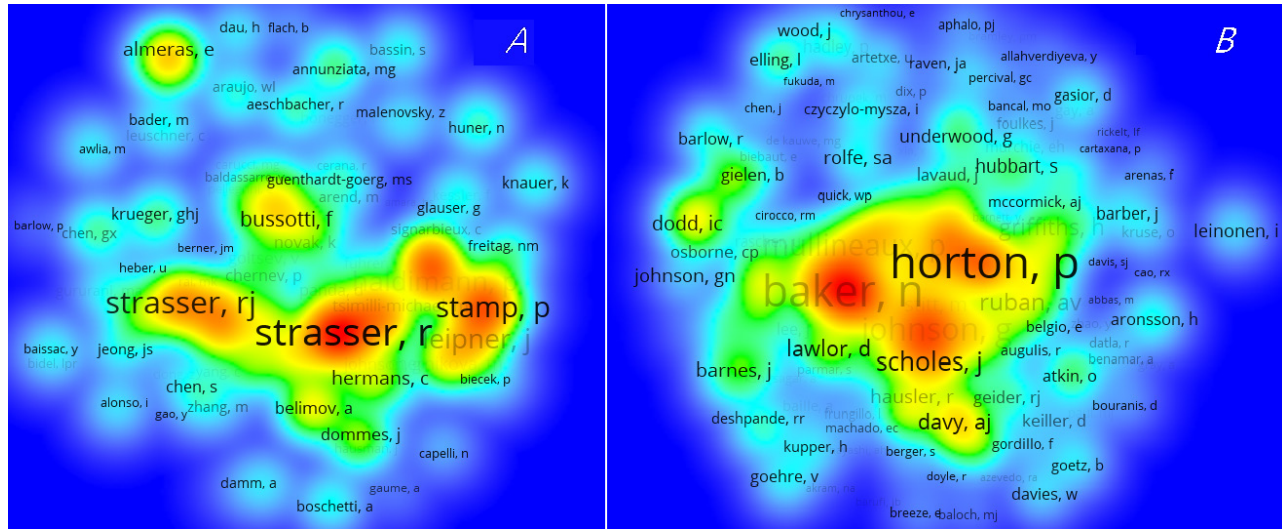

Fig. 1. Co-author network for the academic community of Switzerland $(A)$ and UK ( $B)$ (note that R. Strasser and R.J. Strasser is the same person). From yellow to red, collaboration is stronger and centrality is higher.

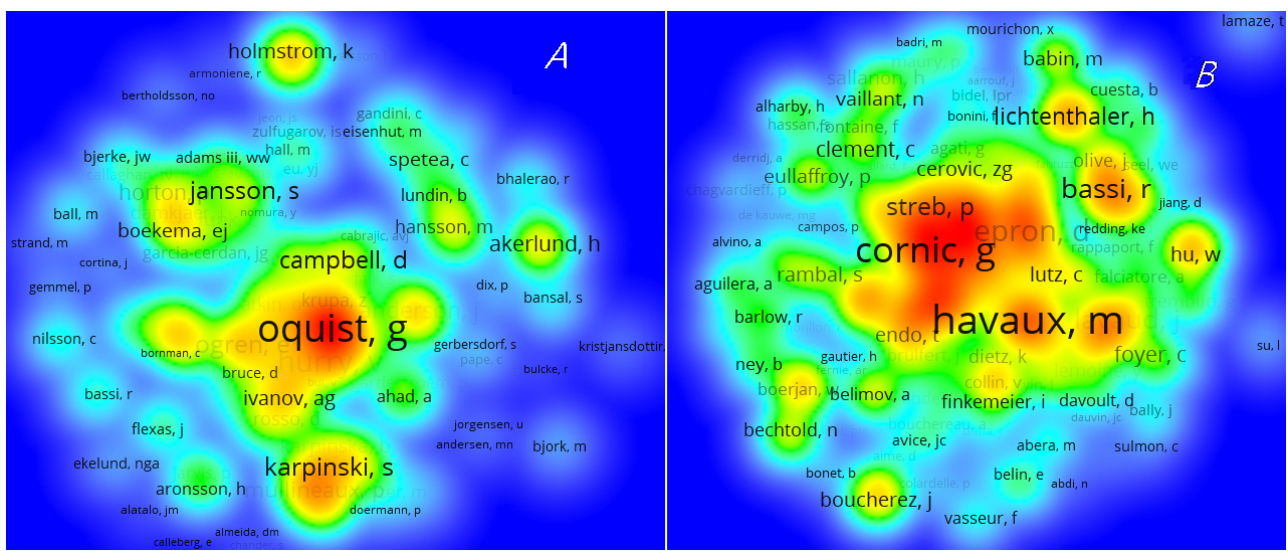

Fig. 2. Co-author network in the academic community of Sweden $(A)$ and France $(B)$. From yellow to red, collaboration is stronger and centrality is higher. 


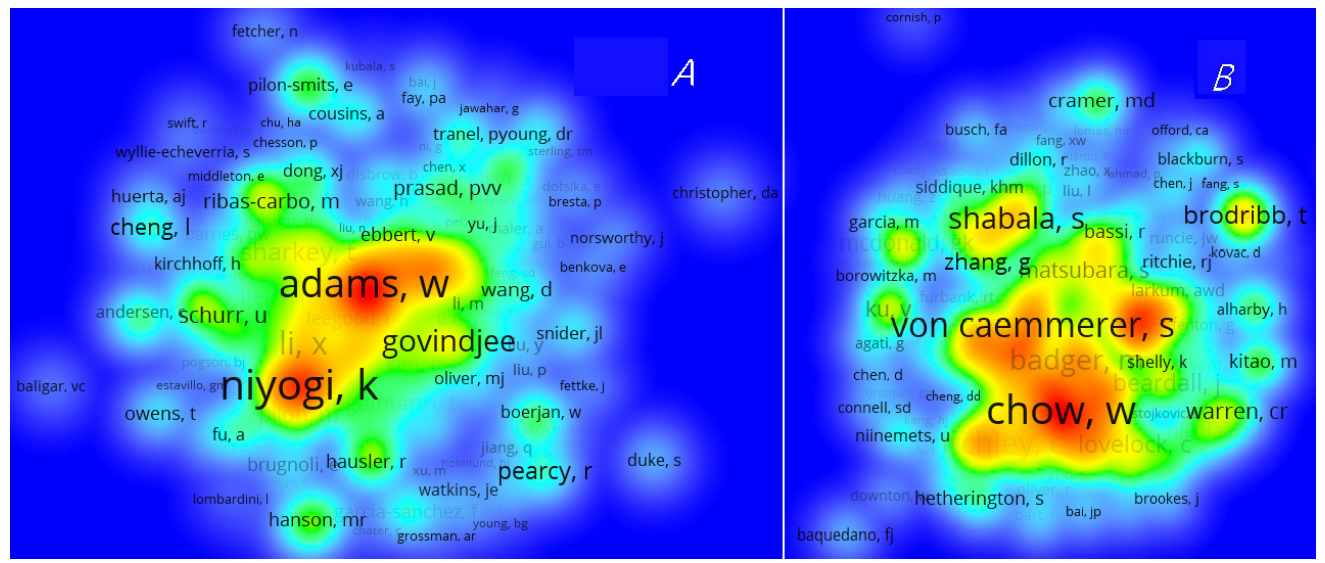

Fig. 3. Co-author network, in the area related to chlorophyll fluorescence, for the academic community of USA $(A)$ and Australia $(B)$. Note that one of us (Govindjee Govindjee) has published with Christa Critchley, Wah Soon (Fred) Chow, both from Australia (see supplement for the publications of Govindjee Govindjee and co-authors for selected references).

in the density map. In Fig. $1 B$, we see that several hotspots emerge in the density map of the co-author network. From red to yellow and from yellow to white, the author density gradually decreases. A high author density means that the author in the area has strong (high) connectivity to authors in the community.

In Fig. $2 A$, we present the author distribution of academic community of Sweden, which had a low number (128) of papers dealing with chlorophyll fluorescence, but on the average, their research has high local citation counts per paper. The following authors were shown to be active there: Gunner Öquist, Stefan Jansson, Erling Ögren, and Kjell-Ove Holmström.

Fig. $2 B$ shows the academic community of France. There were only 326 papers in the period covered. However, on the average, the total local citation score per paper is high. In this analysis, we see the following authors to have been highly active: Michel Havaux, Daniel Epron, Gabriel Cornic, Peter Steb, and Roberto Bassi. (Note that Roberto Bassi is from Italy, but since he is a co-author of a high-IF paper with a corresponding author from France, he is listed in the cluster in this analysis.)

Fig. $3 A$ shows author distribution for the academic community of USA. Although USA is ranked in the fifth place in Table 1, US scientists have contributed the largest number of TLCS, i.e., they have the strongest research focus in this area. Further, the number of authors is the largest among the six countries analyzed above. We note the following US authors in the highlighted areas in Fig. $3 A$ are: William W. Adams, Krishna K. Niyogi, Govindjee Govindjee, and Thomas (Tom) Sharkey. Authors in the highlighted areas of Fig. $3 B$ include: Wah Soon (Fred) Chow, Christa Critchley, Susan Von Caemmerer, and Sergey Shabala.

Active authors in the academic community from different time periods: After we investigated the authors in terms of their countries, we noticed that the 'activeness' of authors is related to time periods. Obviously, no author can be active all the time. Work by beginners needs time to be cited. Senior authors usually have higher number of citations, and their research is conducted in different time periods. Thus, we searched for names of authors from different time periods with the help of software HistCite (Garfield 2009). We ranked the authors by TLCSx, which is TLCS excluding self-citations. The results for 1991 to 2018 are shown in Table 3.

From Table 3, we are able to learn the names of the top authors in the 1991-2018 period. The TLCSx values are slightly smaller in the latter periods than those in the previous periods since the work is more recent. To understand the co-author network visually, we clearly present the top-ten authors from all four periods as follows. Fig. 4 and Fig. 5 show the corresponding author network with author clusters, where the size of author node is proportional to citation count obtained by the authors. Note not all authors are labeled with their names because of the limitation of the visualization space.

In the figures, the authors are depicted as the nodes in the network. The size of the nodes represents the citation counts. The bigger the node, the more important work of the team will be. The representative work of the authors is presented in Table 4

In Table 4, we show data for all periods. Authors in latter period had fewer TLCS than in the earlier time period, indicating that authors from the first time period have been in the field longer and, as a result, their publications are more classical and fundamental.

Visualizing the activities of authors is an important way to understand the dynamics of any research field. Collaboration among the authors indicates social interactions, though complicated; it reveals different characteristics of a field compared to traditional review work. For example, the size of community may describe the ability of the group of the authors. Scientific research is no longer the work of individual researchers, but it is a collaborative effort. An increase in the size of a specific cluster may imply that the particular research community is in a healthy renewing status, absorbing more and more young researchers to the field. Moreover, researchers have the 
Table 3. Active authors from four time periods between 1991 and 2018 in a descending order of TLCSx. Percent is total publication number by the author divided by total publication number by all authors. TLCS/t stands for TLCS divided by total publication number, namely the average TLCS for each paper by this author. TLCSx stands for the citations after self-citations are deleted from the TLCS. "Co-authors of one of us (Govindjee Govindjee, see supplement).

\begin{tabular}{|c|c|c|c|c|c|c|c|c|c|}
\hline & \# & Author & Recs & Percent & TLCS & $\mathrm{TLCS} / \mathrm{t}$ & TLCSx & TGCS & $\mathrm{TGCS} / \mathrm{t}$ \\
\hline \multirow[t]{10}{*}{ 1991-1997 } & 1 & Gunner Öquist & 23 & 2.1 & 261 & 48.87 & 183 & 1,963 & 480.89 \\
\hline & 2 & Peter Horton & 19 & 1.8 & 216 & 47.22 & 165 & 2,010 & 622.33 \\
\hline & 3 & Olle Björkman & 9 & 0.8 & 139 & 29.08 & 114 & 1,130 & 410.95 \\
\hline & 4 & Adam M. Gilmore & 9 & 0.8 & 145 & 34.47 & 114 & 1,365 & 703.35 \\
\hline & 5 & Alexander V. Ruban & 8 & 0.7 & 139 & 33.12 & 109 & 1,094 & 386.20 \\
\hline & 6 & Norman P.A. Huner & 21 & 1.9 & 171 & 33.64 & 107 & 1,479 & 386.99 \\
\hline & 7 & Wah Soon Chow & 19 & 1.8 & 149 & 33.43 & 106 & 1,413 & 511.25 \\
\hline & 8 & Harry Y. Yamamoto & 10 & 0.9 & 132 & 27.22 & 101 & 949 & 199.77 \\
\hline & 9 & Michel Havaux & 15 & 1.4 & 130 & 22.68 & 93 & 1,537 & 424.67 \\
\hline & 10 & Jan M. Anderson & 19 & 1.8 & 131 & 31.27 & 86 & 1,380 & 514.42 \\
\hline \multirow[t]{10}{*}{ 1998-2004 } & 1 & Krishna K. Niyogi & 10 & 0.6 & 154 & 32.72 & 131 & 3,137 & 919.12 \\
\hline & 2 & Neil R. Baker & 15 & 0.9 & 100 & 21.75 & 77 & 1,681 & 590.80 \\
\hline & 3 & William W. Adams & 13 & 0.8 & 98 & 17.00 & 71 & 739 & 156.12 \\
\hline & 4 & Ulrich Heber & 13 & 0.8 & 90 & 18.39 & 67 & 652 & 135.13 \\
\hline & 5 & Arthur R. Grossman & 3 & 0.2 & 75 & 11.67 & 66 & 1,063 & 178.52 \\
\hline & 6 & Barbara Demmig-Adams & 12 & 0.7 & 86 & 15.29 & 64 & 842 & 163.12 \\
\hline & 7 & Olle Björkman & 3 & 0.2 & 74 & 11.32 & 63 & 867 & 138.64 \\
\hline & 8 & Charles Barry Osmond & 11 & 0.7 & 89 & 16.69 & 63 & 648 & 144.07 \\
\hline & 9 & Kevin Oxborough & 12 & 0.7 & 73 & 16.40 & 57 & 1,482 & 656.42 \\
\hline & 10 & Xiaoping Li & 3 & 0.2 & 59 & 15.33 & 53 & 1,491 & 381.21 \\
\hline \multirow[t]{10}{*}{ 2005-2011 } & 1 & Jaume Flexas & 14 & 0.7 & 86 & 17.60 & 65 & 1,536 & 381.77 \\
\hline & 2 & Hipólito Medrano & 11 & 0.5 & 86 & 17.60 & 65 & 1,394 & 295.10 \\
\hline & 3 & Reto Strasser & 24 & 1.2 & 80 & 18.16 & 54 & 1,165 & 382.90 \\
\hline & 4 & Jeroni Galmés & 8 & 0.4 & 65 & 13.27 & 53 & 1,010 & 215.23 \\
\hline & 5 & Hartmut K. Lichtenthaler & 8 & 0.4 & 60 & 9.90 & 42 & 506 & 90.48 \\
\hline & 6 & Claus Buschmann & 10 & 0.5 & 63 & 10.15 & 40 & 450 & 82.45 \\
\hline & 7 & Neil R. Baker & 6 & 0.3 & 42 & 6.17 & 37 & 395 & 110.23 \\
\hline & 8 & Krishna K. Niyogi & 7 & 0.3 & 38 & 6.57 & 37 & 641 & 137.48 \\
\hline & 9 & Congming $\mathrm{Lu}$ & 19 & 0.9 & 53 & 9.45 & 36 & 987 & 235.26 \\
\hline & 10 & Martin Knapp & 2 & 0.1 & 42 & 6.46 & 35 & 286 & 45.94 \\
\hline \multirow[t]{10}{*}{ 2012-2018 } & 1 & Hazem M. Kalaji* $^{*}$ & 23 & 0.8 & 211 & 46.63 & 158 & 589 & 140.25 \\
\hline & 2 & Marian Brestič ${ }^{*}$ & 13 & 0.4 & 174 & 34.88 & 131 & 462 & 104.95 \\
\hline & 3 & Marek Živčák* & 12 & 0.4 & 173 & 34.38 & 130 & 457 & 102.45 \\
\hline & 4 & Suleyman I. Allakhverdiev* & 17 & 0.6 & 140 & 28.76 & 97 & 353 & 79.77 \\
\hline & 5 & Abdallah Oukarroum & 8 & 0.3 & 111 & 21.04 & 88 & 273 & 52.34 \\
\hline & 6 & Reto Strasser & 23 & 0.8 & 118 & 23.66 & 80 & 310 & 60.23 \\
\hline & 7 & Vasilij Goltsev & 7 & 0.2 & 65 & 13.95 & 47 & 162 & 36.18 \\
\hline & 8 & Roberto Bassi & 12 & 0.4 & 54 & 9.10 & 46 & 299 & 61.81 \\
\hline & 9 & Filippo Bussotti & 14 & 0.5 & 76 & 18.42 & 46 & 216 & 55.80 \\
\hline & 10 & Govindjee Govindjee & 13 & 0.4 & 60 & 13.39 & 45 & 147 & 32.68 \\
\hline
\end{tabular}

ability to produce new interesting findings by integrating information from different institutions, different countries, different age groups, and different journals.
Co-author networks have the advantage of objectively revealing the interactions among the authors. However, this is not always effective, because many authors who do 

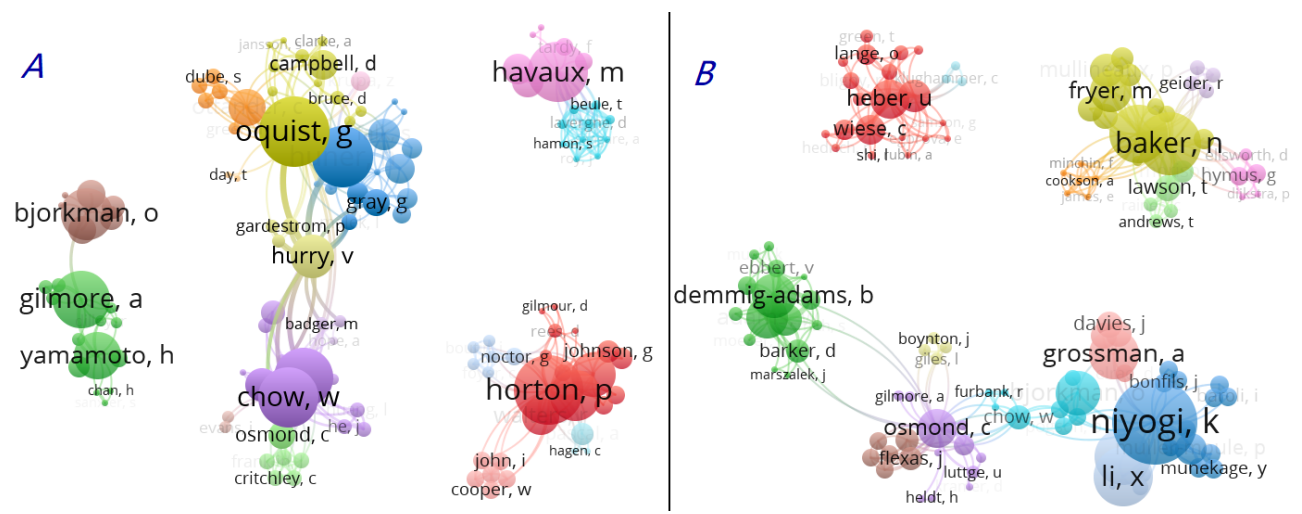

Fig. 4. Co-author network, in the area of chlorophyll fluorescence, for the academic community of active authors from 1991 to 1997 (A) and from 1998 to $2004(B)$.

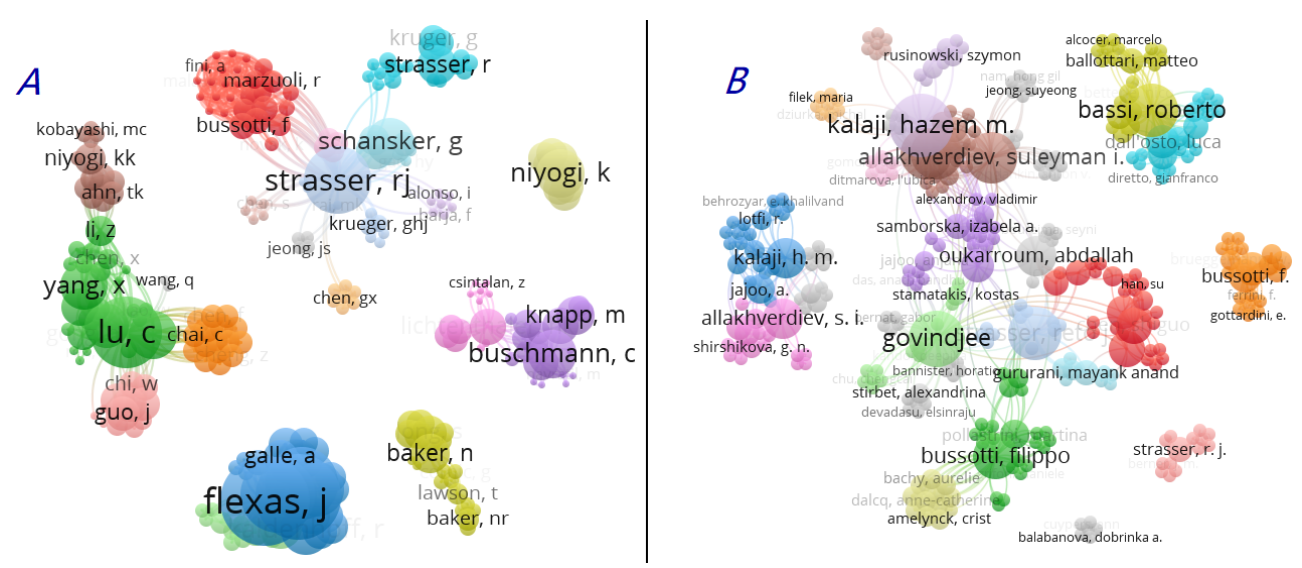

Fig. 5. Co-author network, for chlorophyll fluorescence, for the academic community of active authors from 2005 to $2011(A)$ and from 2012 to $2018(B)$.

not always collaborate with others also make important contributions to the field. Therefore, in terms of knowledge diffusion, author networks have the disadvantage of incompleteness, which can be compensated for by co-word or co-cited reference networks.

Co-cited reference networks as a knowledge mapping: Co-cited references are based on the co-occurrence relationship among the keywords and references. Comparing with the well-known co-word network, there is much more information that exists in the cited references. Generally speaking, each paper may, on average, cite 20 or more papers. With the cited references, co-cited reference network can be built the same way the 'co-word' network is built. If two references are cited in one paper, then the co-citation relation is built as a line that links the two cited reference nodes. In this work, we built the co-cited reference networks and then, by using a network pathfinder algorithm and pruning sliced networks, the co-cited references networks were simplified for easy visualization. In this case, the generated networks contained 78 nodes and 78 edges connecting the nodes (Fig. 6). Six clusters remained after we applied the pruning technology to reduce the network (Fig. 6). The numbering of the clusters in Fig. 6 is according to the size of the cluster instead of the time.

Below, we discuss the clusters in chronological order:

The first period (from 1991 to 1997): Cluster 0 emerged during the same time period as cluster 1 did. Two representative articles in this cluster are: (1) on the basics of chlorophyll fluorescence and photosynthesis (Krause and Weis 1991), and (2) on the response of plants to high light stress (Demmig-Adams and Adams 1992). We selected two representative articles from cluster 2: (1) on the analysis of relationship between the quantum yield of photosynthetic electron transport and the quenching of chlorophyll fluorescence (Genty et al. 1989), and (2) on the investigation on the nomenclature to be used for chlorophyll fluorescence parameters (van Kooten and Snel 1990).

The second period (from 1998 to 2004): Cluster 5 includes the leading work such as the representative work by Adam Gilmore, which is about mechanistic aspects of xanthophyll cycle-dependent photoprotection (Gilmore 1997); the work by Sarvajeet Singh Gill, which is about abiotic stress tolerance in crop plants (Gill and Tuteja 2010); the work by Kozi Asada, which is about the waterwater cycle in chloroplasts (Asada 1999); work by Krishna K. Niyogi, which is about photoprotection (Niyogi 1999). We note that Gilmore (1997) reviews the work he did with 
Table 4. Work by author clusters from four periods between 1991 and 2018.

\begin{tabular}{lll}
\hline Time period & Author clusters & Papers \\
\hline 1991-1997 & $\begin{array}{l}\text { Gunnar Öquist } \\
\text { cluster }\end{array}$ & $\begin{array}{l}\text { - Photoinhibition of photosynthesis represents a mechanism for the long-term regulation of } \\
\text { Photosystem II (Öquist et al. 1992) } \\
\text { • On the relationship between the quantum yield of photosystem II electron transport, as determined } \\
\text { by chlorophyll fluorescence and the quantum yield of } \mathrm{CO}_{2} \text {-dependent } \mathrm{O}_{2} \text { evolution (Öquist and } \\
\end{array}$ \\
& Chow 1992)
\end{tabular}

Peter Horton - Induction of nonphotochemical energy dissipation and absorbance changes in leaves: Evidence cluster for changes in the state of the light-harvesting system of photosystem II in vivo (Ruban et al. 1993) - Regulation of light-harvesting in green plants: Indication by nonphotochemical quenching of chlorophyll fluorescence (Horton et al. 1994)

Michel Havaux - A theoretical and experimentalanalysis of the $\mathrm{q}_{\mathrm{p}}$ and $\mathrm{q}_{\mathrm{N}}$ coefficients of chlorophyll fluorescence cluster quenching and their relation to photochemical and nonphotochemical events (Havaux et al. 1991) - Stress tolerance of photosystem II in vivo: Antagonistic effects of water, heat, and photoinhibition stresses (Havaux 1992)

Adam M. Gilmore - Mechanistic aspects of xanthophyll cycle-dependent photoprotection in higher plant chloroplasts cluster and leaves (Gilmore 1997)

- Linear models relating xanthophylls and lumen acidity to non-photochemical fluorescence quenching: Evidence that antheraxanthin explains zeaxanthin-independent quenching (Gilmore and Yamamoto 1993)

Wah Soon (Fred) - Photoinhibition of photosynthesis represents a mechanism for the long-term regulation of Chow cluster photosystem II (Öquist et al. 1992)

1998-2004 Neil R. Baker • Rapid, noninvasive screening for perturbations of metabolism and plant growth using chlorophyll cluster fluorescence imaging (Barbagallo et al. 2003)

- High resolution imaging of photosynthetic activities of tissues, cells and chloroplasts in leaves (Baker et al. 2001)

C. Barry Osmond - Analysis of the relative increase in photosynthetic $\mathrm{O}_{2}$ uptake when photosynthesis in grapevine cluster leaves is inhibited following low night temperatures and/or water stress (Flexas et al. 1999)

- A comparison of $\mathrm{CO}_{2}$ and $\mathrm{O}_{2}$ exchange patterns and the relationship with chlorophyll fluorescence during photosynthesis in $\mathrm{C}_{3}$ and CAM plants (Maxwell et al. 1998)

Krishna K. Niyogi - Arabidopsis mutants define a central role for the xanthophyll cycle in the regulation of cluster photosynthetic energy conversion (Niyogi et al. 1998)

- Photoprotection in a zeaxanthin- and lutein-deficient double mutant of Arabidopsis (Niyogi et al. 2001)

Barbara Demmig- - Two forms of sustained xanthophyll cycle-dependent energy dissipation in overwintering Adams cluster Euonymus kiautschovicus (Verhoeven et al. 1998)

- Antioxidants and xanthophyll cycle-dependent energy dissipation in Cucurbita pepo L. and Vinca major L. acclimated to four growth PPFDs in the field (Logan et al. 1998)

Ulrich Heber (more - Heat sensitivity of chloroplasts and leaves: Leakage of protons from thylakoids and reversible often as a co-author) activation of cyclic electron transport (Bukhov et al. 1999)

cluster - Phototolerance of lichens, mosses and higher plants in an alpine environment: Analysis of photoreactions (Heber et al. 2000)

2005-2011 Reto Strasser - Probing the responses of barley cultivars (Hordeum vulgare L.) by chlorophyll a fluorescence OLKJIP under drought stress and re-watering (Oukarroum et al. 2007)

- Ranking of dark chilling tolerance in soybean genotypes probed by the chlorophyll $a$ fluorescence transient O-J-I-P (Strauss et al. 2006)

Jaume Flexas - Photosynthetic limitations in response to water stress and recovery in Mediterranean plants with cluster different growth forms (Galmés et al. 2007)

Rapid variations of mesophyll conductance in response to changes in $\mathrm{CO}_{2}$ concentration around leaves (Flexas et al. 2007)

Claus Buschmann • How to correctly determine the different chlorophyll fluorescence parameters and the chlorophyll and Hartmut K. Lichtenthaler cluster fluorescence decrease ratio $\mathrm{R}_{\mathrm{Fd}}$ of leaves with the PAM fluorometer (Lichtenthaler et al. 2005a)

- Chlorophyll fluorescence imaging of photosynthetic activity with the flash-lamp fluorescence imaging system (Lichtenthaler et al. 2005b)

Cong Ming Lu cluster

- LOW PSII ACCUMULATION1 is involved in efficient assembly of photosystem II in Arabidopsis thaliana (Peng et al. 2006)

- Mutations of genes in synthesis of the carotenoid precursors of ABA lead to pre-harvest sprouting and photo-oxidation in rice (Fang et al. 2008) 
Neil R. Baker - Chlorophyll $a$ fluorescence induction kinetics in leaves predicted from a model describing each cluster discrete step of excitation energy and electron transfer associated with Photosystem II (Zhu et al. 2005)

- Low growth temperatures modify the efficiency of light use by photosystem II for $\mathrm{CO}_{2}$ assimilation in leaves of two chilling-tolerant $\mathrm{C}_{4}$ species, Cyperus longus L. and Miscanthus $\times$ giganteus (Farage et al. 2006)

Krishna K. Niyogi - Is PsbS the site of non-photochemical quenching in photosynthesis? (Niyogi et al. 2005)

cluster $\quad$ Two P-type ATPases are required for copper delivery in Arabidopsis thaliana chloroplasts (AbdelGhany et al. 2005)

2012-2018 Hazem M. Kalaji • Effects of salt stress on photosystem II efficiency and $\mathrm{CO}_{2}$ assimilation of two Syrian barley and Suleyman I. landraces (Kalaji et al. 2011)

Allakhverdiev - Photosystem II thermostability in situ: Environmentally induced acclimation and genotypecluster specific reactions in Triticum aestivum L. (Brestič et al. 2012)

Reto Strasser - The IP amplitude of the fluorescence rise OJIP is sensitive to changes in the photosystem I content cluster of leaves: A study on plants exposed to magnesium and sulfate deficiencies, drought stress and salt stress (Ceppi et al. 2012)

- Heat stress and the photosynthetic electron transport chain of the lichen Parmelina tiliacea (Hoffm.) Ach. in the dry and the wet state: Differences and similarities with the heat stress response of higher plants (Oukarroum et al. 2012)

Abdallah - Identification of nutrient deficiency in maize and tomato plants by in vivo chlorophyll $a$ Oukarroum cluster fluorescence measurements (Kalaji et al. 2014)

- The IP amplitude of the fluorescence rise OJIP is sensitive to changes in the photosystem I content of leaves: A study on plants exposed to magnesium and sulfate deficiencies, drought stress and salt stress (Ceppi et al. 2012)

Roberto Bassi - The Arabidopsis szll mutant reveals a critical role of $\beta$-carotene in photosystem I photoprotection cluster (Cazzaniga et al. 2012)

- Zeaxanthin binds to light-harvesting complex stress-related protein to enhance nonphotochemical quenching in Physcomitrella patens (Pinnola et al. 2013)

Govindjee - Effects of salt stress on photosystem II efficiency and $\mathrm{CO}_{2}$ assimilation of two Syrian barley Govindjee landraces (Kalaji et al. 2011)

cluster $\quad$ Photosynthetic responses of sun- and shade-grown barley leaves to high light: Is the lower PSII connectivity in shade leaves associated with protection against excess of light? (Živčák et al. 2014) - The slow S to M rise of chlorophyll $a$ fluorescence reflects transition from state 2 to state 1 in the green alga Chlamydomonas reinhardtii (Kodru et al. 2015)

Govindjee, Harry Yamamoto, and others, whereas Patricia Müller reviews the work she did with Krishna (Kris) Niyogi and others (Müller et al. 2001). Such interactions are important for the growth of the field. The key work conducted by Gilmore and one of us (Govindjee) is cited in the reference section (Gilmore et al. 1995, 1996, 1998, 2000).

The third period (from 2005 to 2011): Cluster 3 includes the work of Kate Maxwell, which is a practical guide for chlorophyll fluorescence (Maxwell and Johnson 2000) and the work of Patricia Müller, which is about the response to excess light energy (Müller et al. 2001). This cluster is the representative cluster in the period from 2005 to 2011 .

The fourth period (from 2012 to 2018): Cluster 1 has three representative references: (1) the work of Neil Baker in 2008 (Baker 2008), which is a review of chlorophyll fluorescence as a probe for photosynthesis in vivo; (2) the work of Reto Strasser in 2010 (Strasser et al. 2010), which is about simultaneous in vivo recording of prompt and delayed fluorescence; and (3) the work of Sandra Stirbet in 2011 (Stirbet and Govindjee 2011). Cluster 4 has two representative papers: (1) the work by Rana Munns in 2008, which is about salinity tolerance (Munns and Tester 2008), and (2) the work of M.M. Chaves in 2009, which is about photosynthesis under drought and salt stress (Chaves et al. 2009). As noted above, this cluster has been actively cited in the period from 2012 to 2018.

\section{Discussion and conclusion}

Several recent publications have started the data-driven analysis for understanding the rapid developing topic of 'chlorophyll fluorescence' (Bąba et al. 2019). This paper is of much use to the readers who are interested in the field of chlorophyll fluorescence to quickly understand the knowledge distribution from disciplinary level in a historical way, providing objective and reliable insights for this active field. In this paper, we have not only extended the work of Baba et al. (2019), but have provided an overall landscape of research on chlorophyll fluorescence from different perspectives using scientometric-based data analysis but in a more detailed way. With similar network based analysis method, we have probed the field with more details by analyzing the clusters extracted from the obtained networks. We analyzed the domain research through authors' social activities and 'knowledgespreading' activities by using co-author networks and cocitation networks.

Top high-citation-per-paper countries are UK, Sweden, France, Australia, and USA (Table 1), but research in other countries are equally important to have built the 


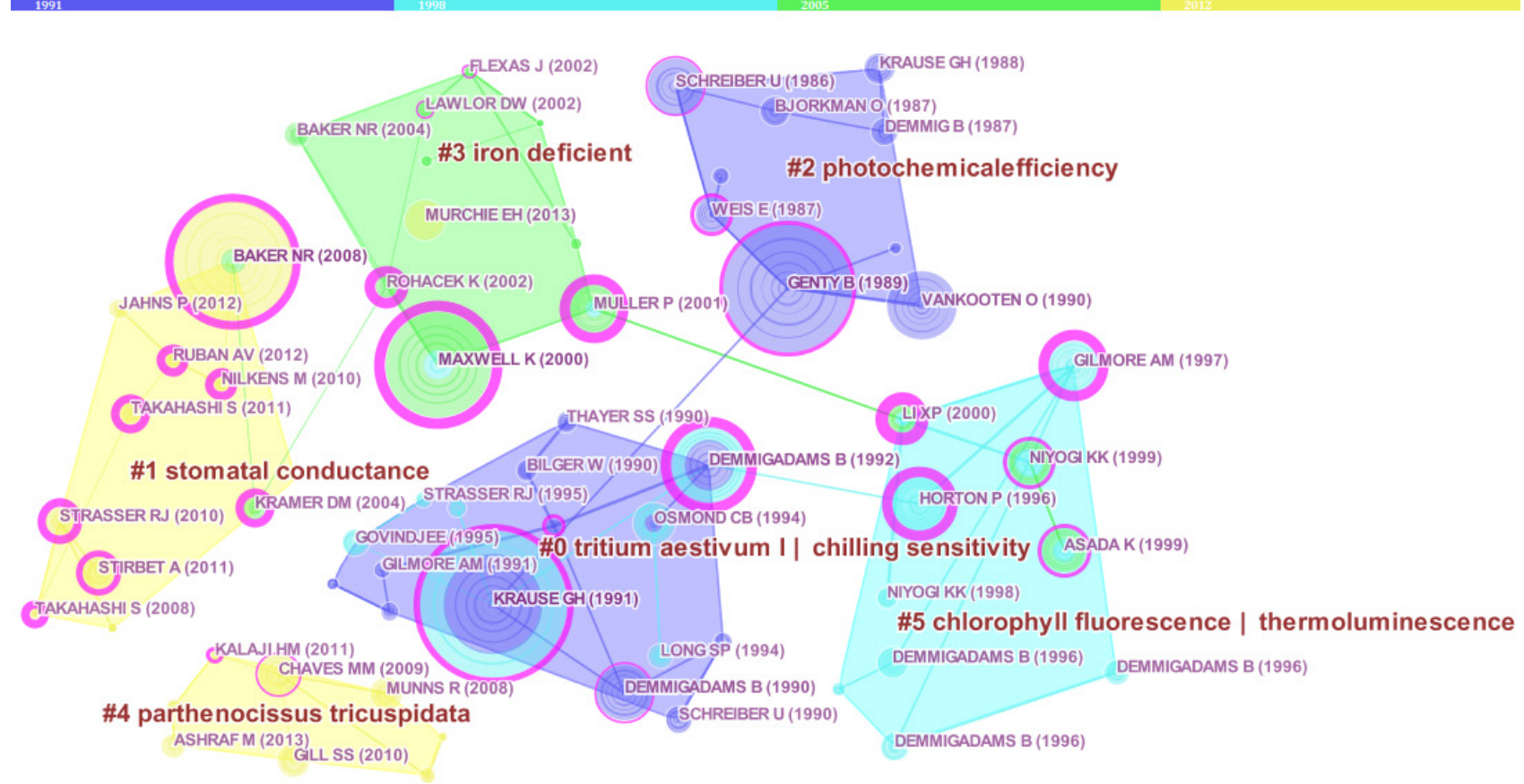

Fig. 6. The co-cited reference network. Different colors correspond to different time periods. The node size corresponds to the citation counts received by the reference node. The polygons stand for the clusters. The labels in red over the clusters stand for the representative topic of the cluster.

knowledge base for the solution of important problems. The analysis by co-author networks shows that the number of co-authors is often an important parameter for evaluating the 'activeness' of academic author clusters. Without considering the quality of published work, the size (number) of co-authorship may lead to errors in the analysis and conclusion. Consideration of both the size and impact at the same time is expected to provide better results. Thus, we used the high-average-TLCS countries as the filter to investigate the author distribution in the top six countries (Table 1). For the field examined here, representative authors were identified.

We remind the readers that different authors are active in different time periods; thus, we have searched for and analyzed the active authors in different time spans with TLCSx as an indicator, which is the local citation count excluding self-citations. We found that in different time periods, the top active authors are almost always different. In some cases, the same authors emerged in two-time spans, which means that this field is active and excellent authors remain active across several time spans. In this paper, we have identified active working author clusters in different time periods from co-author networks.

Lastly, we have analyzed the overall evolution of this domain through co-word and co-cited reference networks. A co-word network is based on the keyword list in each of the papers in the bibliographic datasets, and it can be regarded, roughly, as a knowledge-level representation. Since authors without knowing each other can share and work on similar topics, we can regard this as a more loosely coupled relation than the actual co-authorship. Thus, what is revealed by co-word networks can be more flexible and more towards the knowledge itself. Similar to the co-word networks, co-cited reference networks also show relationships without the authors actually knowing each other; thus, they can be regarded as a knowledge representation in a more detailed and intricate manner.

There are still some limitations for the type of analysis conducted here. For example, G. Govindjee (one of the authors of this paper), who had earlier used one name only, has been shown (unpublished observation) not be associated with all his publications in the database. We note that many of his papers appear in published databases without his name. Thus, his contributions and those by others like him (if any) are underestimated. Some other authors are also actively working in the related field, e.g., George C. Papageorgiou from Greece, Bernard Genty, and Ismael Moya from France. In addition, we mention the late Jean-Marie Briantais, who did pioneering work in this field (see de Kouchkovsky and Cerovic 2005). They may not have published papers in the journals categorized in 'Plant Science' in WoS. These authors were thus not included in the analyzed datasets. Since it is hard to introduce every research group in the paper, we have only studied the groups in the top six high-average-TLCS countries; thus, some important authors in the field may not have been included in the analysis. This is another limitation of the work. We hope to extend this analysis in the future with these caveats in mind. 


\section{References}

Abdel-Ghany S.E., Müller-Moulé P., Niyogi K.K. et al.: Two P-type ATPases are required for copper delivery in Arabidopsis thaliana chloroplasts. - Plant Cell 17: 1233-1251, 2005.

Andersson J., Walters R.G., Horton P., Jansson S.: Antisense inhibition of the photosynthetic antenna proteins CP29 and CP26: Implications for the mechanism of protective energy dissipation. - Plant Cell 13: 1193-1204, 2001

Asada K.: The water-water cycle in chloroplasts: Scavenging of active oxygens and dissipation of excess photons. - Annu. Rev. Plant Phys. 50: 601-639, 1999.

Atal N., Saradhi P.P., Mohanty P.: Inhibition of the chloroplast photochemical reactions by treatment of wheat seedlings with low concentrations of cadmium: Analysis of electron transport activities and changes in fluorescence yield. - Plant Cell Physiol. 32: 943-951, 1991.

Bąba W., Kompała-Bąba A., Zabochnicka-Świątek M. et al.: Discovering trends in photosynthesis using modern analytical tools: More than 100 reasons to use chlorophyll fluorescence. - Photosynthetica 57: 668-679, 2019.

Baker N.R.: Chlorophyll fluorescence: A probe of photosynthesis in vivo. - Annu. Rev. Plant Biol. 59: 89-113, 2008.

Baker N.R., Oxborough K., Lawson T., Morison J.I.L.: High resolution imaging of photosynthetic activities of tissues, cells and chloroplasts in leaves. - J. Exp. Bot. 52: 615-621, 2001.

Barbagallo R.P., Oxborough K., Pallett K.E., Baker N.R.: Rapid, noninvasive screening for perturbations of metabolism and plant growth using chlorophyll fluorescence imaging. - Plant Physiol. 132: 485-493, 2003.

Beaver D., Rosen R.: Studies in scientific collaboration: Part I. The professional origins of scientific co-authorship. Scientometrics 1: 65-84, 1978.

Björn L.O., Papageorgiou G.C., Blankenship R.E., Govindjee: A viewpoint: Why chlorophyll $a$ ? - Photosynth. Res. 99: 85-98, 2009

Brestič M., Živčák M., Kalaji H.M. et al.: Photosystem II thermostability in situ: Environmentally induced acclimation and genotype-specific reactions in Triticum aestivum L. Plant. Physiol. Bioch. 57: 93-105, 2012.

Bukhov N.G., Wiese C., Neimanis S., Heber U.: Heat sensitivity of chloroplasts and leaves: Leakage of protons from thylakoids and reversible activation of cyclic electron transport. Photosynth. Res. 59: 81-93, 1999.

Bussotti F., Desotgiu R., Cascio C. et al.: Ozone stress in woody plants assessed with chlorophyll $a$ fluorescence. A critical reassessment of existing data. - Environ. Exp. Bot. 73: 19-30, 2011.

Callon M., Courtial J.-P., Laville F.: Co-word analysis as a tool for describing the network of interactions between basic and technological research: The case of polymer chemistry. Scientometrics 22: 155-205, 1991.

Cazzaniga S., Li Z., Niyogi K.K. et al.: The Arabidopsis szll mutant reveals a critical role of $\beta$-carotene in photosystem I photoprotection. - Plant Physiol. 159: 1745-1758, 2012.

Ceppi M.G., Oukarroum A., Çiçek N. et al.: The IP amplitude of the fluorescence rise OJIP is sensitive to changes in the photosystem I content of leaves: A study on plants exposed to magnesium and sulfate deficiencies, drought stress and salt stress. - Physiol. Plantarum 144: 277-288, 2012.

Chaves M.M., Flexas J., Pinheiro C.: Photosynthesis under drought and salt stress: Regulation mechanisms from whole plant to cell. - Ann. Bot.-London 103: 551-560, 2009.

Chen C., Morris S.: Visualizing evolving networks: Minimum spanning trees versus pathfinder networks. IEEE Symposium on Information Visualization 2003. Pp. 67-74. IEEE, Seattle
2003.

Chen K., Guan J.: A bibliometric investigation of research performance in emerging nanobiopharmaceuticals. J. Informetr. 5: 233-247, 2011.

Cornic G., Briantais J.M.: Partitioning of photosynthetic electron flow between $\mathrm{CO}_{2}$ and $\mathrm{O}_{2}$ reduction in a $\mathrm{C}_{3}$ leaf (Phaseolus vulgaris L.) at different $\mathrm{CO}_{2}$ concentrations and during drought stress. - Planta 183: 178-184, 1991.

Dall'Osto L., Caffarri S., Bassi R.: A mechanism of nonphotochemical energy dissipation, independent from PsbS, revealed by a conformational change in the antenna protein CP26. Plant Cell 17: 1217-1232, 2005.

de Kouchkovsky Y., Cerovic Z.G.: Jean-Marie Briantais (19362004), a friend and a champion of interactive and integrative research - Obituary. - Photosynth. Res. 83: 1-3, 2005.

Demmig-Adams B., Adams III W.W.: Photoprotection and other responses of plants to high light stress. - Annu. Rev. Plant Phys. 43: 599-626, 1992.

Demmig-Adams B., Adams III W.W.: Xanthophyll cycle and light stress in nature: Uniform response to excess direct sunlight among higher plant species. - Planta 198: 460-470, 1996.

Demmig-Adams B., Adams III W.W., Barker D.H. et al.: Using chlorophyll fluorescence to assess the fraction of absorbed light allocated to thermal dissipation of excess excitation. Physiol. Plantarum 98: 253-264, 1996.

Djanaguiraman M., Devi D.D., Shanker A.K. et al.: Selenium an antioxidative protectant in soybean during senescence. Plant Soil 272: 77-86, 2005.

Epron D., Godard D., Cornic G., Genty B: Limitation of net $\mathrm{CO}_{2}$ assimilation rate by internal resistances to $\mathrm{CO}_{2}$ transfer in the leaves of two tree species (Fagus sylvatica L. and Castanea sativa Mill.). - Plant Cell. Environ. 18: 43-51, 1995.

Fang J., Chai C., Qian Q. et al.: Mutations of genes in synthesis of the carotenoid precursors of ABA lead to pre-harvest sprouting and photo-oxidation in rice. - Plant J. 54: 177-189, 2008.

Farage P.K., Blowers D., Long S.P., Baker N.R.: Low growth temperatures modify the efficiency of light use by photosystem II for $\mathrm{CO}_{2}$ assimilation in leaves of two chillingtolerant $\mathrm{C}_{4}$ species, Cyperus longus L. and Miscanthus $\times$ giganteus. - Plant Cell. Environ. 29: 720-728, 2006.

Flexas J., Badger M., Chow W.S. et al.: Analysis of the relative increase in photosynthetic $\mathrm{O}_{2}$ uptake when photosynthesis in grapevine leaves is inhibited following low night temperatures and/or water stress. - Plant Physiol. 121: 675-684, 1999.

Flexas J., Diaz-Espejo A., Galmés J. et al.: Rapid variations of mesophyll conductance in response to changes in $\mathrm{CO}_{2}$ concentration around leaves. - Plant Cell. Environ. 30: 12841298, 2007.

Fracheboud Y., Haldimann P., Leipner J., Stamp P.: Chlorophyll fluorescence as a selection tool for cold tolerance of photosynthesis in maize (Zea mays L.). - J. Exp. Bot. 50: 1533$1540,1999$.

Fryer M.J., Ball L., Oxborough K. et al.: Control of Ascorbate Peroxidase 2 expression by hydrogen peroxide and leaf water status during excess light stress reveals a functional organisation of Arabidopsis leaves. - Plant J. 33: 691-705, 2003.

Fryer M.J., Oxborough K., Mullineaux P.M., Baker N.R.: Imaging of photo-oxidative stress responses in leaves. J. Exp. Bot. 53: 1249-1254, 2002.

Galmés J., Medrano H., Flexas J.: Photosynthetic limitations in response to water stress and recovery in Mediterranean plants with different growth forms. - New Phytol. 175: 81-93, 2007.

Garfield E.: From the science of science to Scientometrics 
visualizing the history of science with HistCite software. J. Informetr. 3: 173-179, 2009.

Gastellu-Etchegorry J.P., Lauret N., Yin T. et al.: DART: Recent advances in remote sensing data modeling with atmosphere, polarization, and chlorophyll fluorescence. - IEEE J. Sel. Top. Appl. 10: 2640-2649, 2017.

Genty B., Briantais J., Baker N.R.: The relationship between the quantum yield of photosynthetic electron transport and quenching of chlorophyll fluorescence. - BBA-Gen. Subjects 990: 87-92, 1989.

Gill S.S., Tuteja N.: Reactive oxygen species and antioxidant machinery in abiotic stress tolerance in crop plants. - Plant Physiol. Bioch. 48: 909-930, 2010.

Gilmore A.M.: Mechanistic aspects of xanthophyll cycledependent photoprotection in higher plant chloroplasts and leaves. - Physiol. Plantarum 99: 197-209, 1997.

Gilmore A.M., Hazlett T.L., Debrunner P.G., Govindjee: Photosystem II chlorophyll $a$ fluorescence lifetimes and intensity are independent of the antenna size differences between barley wild-type and chlorina mutants: Photochemical quenching and xanthophyll cycle-dependent nonphotochemical quenching of fluorescence. - Photosynth. Res. 48: 171-187, 1996.

Gilmore A.M., Hazlett T.L., Govindjee: Xanthophyll cycledependent quenching of photosystem II chlorophyll $a$ fluorescence: Formation of a quenching complex with a short fluorescence lifetime. - P. Natl. Acad. Sci. USA 92: 22732277, 1995.

Gilmore A.M., Itoh S., Govindjee: Global spectral-kinetic analysis of room temperature chlorophyll $a$ fluorescence from light-harvesting antenna mutants of barley. - Philos. T. Roy. Soc. B. 355: 1371-1384, 2000.

Gilmore A.M., Shinkarev V.P., Hazlett T.L., Govindjee: Quantitative analysis of the effects of intrathylakoid $\mathrm{pH}$ and xanathophyll cycle pigments on chlorophyll $a$ fluorescence lifetime distributions and intensity in thylakoids. Biochemistry-US 37: 13582-13593, 1998.

Gilmore A.M., Yamamoto H.Y.: Linear models relating xanthophylls and lumen acidity to non-photochemical fluorescence quenching: Evidence that antheraxanthin explains zeaxanthin-independent quenching. - Photosynth. Res. 35: 67-78, 1993

Govindjee G.: Sixty-three years since Kautsky: Chlorophyll $a$ fluorescence. - Aust. J. Plant Physiol. 22: 131-160, 1995.

Gravano E., Bussotti F., Strasser R.J. et al.: Ozone symptoms in leaves of woody plants in open-top chambers: Ultrastructural and physiological characteristics. - Physiol. Plantarum 121: 620-633, 2004

Guanter L., Köhler P., Walther S., Zhang Y.G.: Recent advances in global monitoring of terrestrial sun-induced chlorophyll fluorescence. 2016 IEEE International Geoscience and Remote Sensing Symposium. Pp. 1714-1716. IEEE, Beijing 2016.

Guo Y., Tan J.: Recent advances in the application of chlorophyll $a$ fluorescence from photosystem II. - Photochem. Photobiol. 91: 1-14, 2015

Havaux M.: Stress tolerance of photosystem II in vivo: Antagonistic effects of water, heat, and photoinhibition stresses. - Plant Physiol. 100: 424-432, 1992.

Havaux M.: Characterization of thermal damage to the photosynthetic electron transport system in potato leaves. Plant Sci. 94: 19-33, 1993.

Havaux M., Dall'Osto L., Bassi R.: Zeaxanthin has enhanced antioxidant capacity with respect to all other xanthophylls in Arabidopsis leaves and functions independent of binding to PSII antennae. - Plant Physiol. 145: 1506-1520, 2007.
Havaux M., Strasser R.J., Greppin H.: A theoretical and experimental analysis of the $\mathrm{q}_{\mathrm{P}}$ and $\mathrm{q}_{\mathrm{N}}$ coefficients of chlorophyll fluorescence quenching and their relation to photochemical and nonphotochemical events. - Photosynth. Res. 27: 41-55, 1991.

He Q.H., Wang G., Luo L. et al.: Mapping the managerial areas of Building Information Modeling (BIM) using scientometric analysis. - Int. J. Proj. Manag. 35: 670-685, 2017.

Heber U., Bilger W., Bligny R., Lange O.L.: Phototolerance of lichens, mosses and higher plants in an alpine environment: Analysis of photoreactions. - Planta 211: 770-780, 2000.

Hendrickson L., Furbank R.T., Chow W.S.: A simple alternative approach to assessing the fate of absorbed light energy using chlorophyll fluorescence. - Photosynth. Res. 82: 73-81, 2004.

Hideg É., Barta C., Kálai T. et al.: Detection of singlet oxygen and superoxide with fluorescent sensors in leaves under stress by photoinhibition or UV radiation. - Plant Cell Physiol. 43: 1154-1164, 2002.

Hirsch J.E.: An index to quantify an individual's scientific research output. - P. Natl. Acad. Sci. USA 102: 16569-16572, 2005.

Holmström K.-O., Somersalo S., Mandal A. et al.: Improved tolerance to salinity and low temperature in transgenic tobacco producing glycine betaine. - J. Exp. Bot. 51: 177-185, 2000.

Horton P., Ruban A.V.: Molecular design of the photosystem II light-harvesting antenna: Photosynthesis and photoprotection. - J. Exp. Bot. 56: 365-373, 2004.

Horton P., Ruban A.V., Walters R.G.: Regulation of lightharvesting in green plants: Indication by nonphotochemical quenching of chlorophyll fluorescence. - Plant Physiol. 106: 415-420, 1994.

Horváth E.M., Peter S.O., Joët T. et al.: Targeted inactivation of the plastid $n d h B$ gene in tobacco results in an enhanced sensitivity of photosynthesis to moderate stomatal closure. Plant Physiol. 123: 1337-1350, 2000.

Hu K., Liu J., Li B. et al.: Global research trends in food safety in agriculture and industry from 1991 to 2018: A data-driven analysis. - Trends Food Sci. Tech. 85: 262-276, 2019.

Hu K., Qi K., Guan Q. et al.: A scientometric visualization analysis for night-time light remote sensing research from 1991 to 2016. - Remote. Sens.-Basel 9: 802, 2017.

Hu K., Qi K., Yang S. et al.: Identifying the "Ghost City" of domain topics in a keyword semantic space combining citations. - Scientometrics 114: 1141-1157, 2018a.

Hu K., Wu H., Qi K. et al.: A domain keyword analysis approach extending Term Frequency-Keyword Active Index with Google Word2Vec model. - Scientometrics 114: 1031-1068, $2018 b$.

Janda T., Szalai G., Tari I., Páldi E.: Hydroponic treatment with salicylic acid decreases the effects of chilling injury in maize (Zea mays L.) plants. - Planta 208: 175-180, 1999.

Johnson G.N., Young A.J., Scholes J.D., Horton P.: The dissipation of excess excitation energy in British plant species. Plant Cell. Environ. 16: 673-679, 1993.

Kalaji H.M., Govindjee, Bosa K. et al.: Effects of salt stress on photosystem II efficiency and $\mathrm{CO}_{2}$ assimilation of two Syrian barley landraces. - Environ. Exp. Bot. 73: 64-72, 2011.

Kalaji H.M., Oukarroum A., Alexandrov V. et al.: Identification of nutrient deficiency in maize and tomato plants by in vivo chlorophyll $a$ fluorescence measurements. - Plant Physiol. Bioch. 81: 16-25, 2014

Kodru S., Malavath T., Devadasu E. et al.: The slow $\mathrm{S}$ to $\mathrm{M}$ rise of chlorophyll $a$ fluorescence reflects transition from state 2 to state 1 in the green alga Chlamydomonas reinhardtii. Photosynth. Res. 125: 219-231, 2015.

Kovács L., Damkjær J., Kereïche S. et al.: Lack of the light- 
harvesting complex CP24 affects the structure and function of the grana membranes of higher plant chloroplasts. - Plant Cell 18: 3106-3120, 2006.

Krause G.H., Weis E.: Chlorophyll fluorescence and photosynthesis: The basics. - Annu. Rev. Plant Phys. 42: 313-349, 1991.

Leipner J., Fracheboud Y., Stamp P.: Effect of growing season on the photosynthetic apparatus and leaf antioxidative defenses in two maize genotypes of different chilling tolerance. Environ. Exp. Bot. 42: 129-139, 1999.

Lichtenthaler H.K., Buschmann C., Knapp M.: How to correctly determine the different chlorophyll fluorescence parameters and the chlorophyll fluorescence decrease ratio $\mathrm{R}_{\mathrm{Fd}}$ of leaves with the PAM fluorometer. - Photosynthetica 43: 379-393, 2005a.

Lichtenthaler H.K., Langsdorf G., Lenk S., Buschmann C.: Chlorophyll fluorescence imaging of photosynthetic activity with the flash-lamp fluorescence imaging system. Photosynthetica 43: 355-369, 2005b.

Liu C., Gui Q.: Mapping intellectual structures and dynamics of transport geography research: A scientometric overview from 1982 to 2014. - Scientometrics 109: 159-184, 2016.

Logan B.A., Demmig-Adams B., Adams III W.W., Grace S.C.: Antioxidants and xanthophyll cycle-dependent energy dissipation in Cucurbita pepo L. and Vinca major L. acclimated to four growth PPFDs in the field. - J. Exp. Bot. 49: 1869-1879, 1998.

Loreto F., Harley P.C., Di Marco G., Sharkey T.D.: Estimation of mesophyll conductance to $\mathrm{CO}_{2}$ flux by three different methods. - Plant Physiol. 98: 1437-1443, 1992.

Marschall M., Proctor M.C.F.: Are bryophytes shade plants? Photosynthetic light responses and proportions of chlorophyll $a$, chlorophyll $b$ and total carotenoids. - Ann. Bot.London 94: 593-603, 2004.

Maxwell K., Badger M.R., Osmond C.B.: A comparison of $\mathrm{CO}_{2}$ and $\mathrm{O}_{2}$ exchange patterns and the relationship with chlorophyll fluorescence during photosynthesis in $\mathrm{C}_{3}$ and CAM plants. Aust. J. Plant Physiol. 25: 45-52, 1998.

Maxwell K., Johnson G.N.: Chlorophyll fluorescence a practical guide. - J. Exp. Bot. 51: 659-668, 2000.

Mehta P., Jajoo A., Mathur S., Bharti S.: Chlorophyll a fluorescence study revealing effects of high salt stress on Photosystem II in wheat leaves. - Plant Physiol. Bioch. 48: 16-20, 2010.

Melin G., Persson O.: Studying research collaboration using co-authorships. - Scientometrics 36: 363-377, 1996.

Mishra R.K., Singhal G.S.: Function of photosynthetic apparatus of intact wheat leaves under high light and heat stress and its relationship with peroxidation of thylakoid lipids. - Plant Physiol. 98: 1-6, 1992.

Müller P., Li X.P., Niyogi K.K.: Non-photochemical quenching. A response to excess light energy. - Plant Physiol. 125: 15581566, 2001.

Munns R., Tester M.: Mechanisms of salinity tolerance. - Annu. Rev. Plant Biol. 59: 651-681, 2008.

Niyogi K.K.: Photoprotection revisited: Genetic and molecular approaches. - Annu. Rev. Plant Phys. 50: 333-359, 1999.

Niyogi K.K., Björkman O., Grossman A.R.: Chlamydomonas xanthophyll cycle mutants identified by video imaging of chlorophyll fluorescence quenching. - Plant Cell 9: 13691380, 1997.

Niyogi K.K., Grossman A.R., Björkman O.: Arabidopsis mutants define a central role for the xanthophyll cycle in the regulation of photosynthetic energy conversion. - Plant Cell 10: 11211134, 1998.

Niyogi K.K., Li X.P., Rosenberg V., Jung H.S.: Is PsbS the site of non-photochemical quenching in photosynthesis? - J. Exp. Bot. 56: 375-382, 2005.

Niyogi K.K., Shih C., Soon C.W. et al.: Photoprotection in a zeaxanthin- and lutein-deficient double mutant of Arabidopsis. - Photosynth. Res. 67: 139-145, 2001.

Ögren E., Evans J.R.: Photosynthetic light-response curves: I. The influence of $\mathrm{CO}_{2}$ partial pressure and leaf inversion. Planta 189: 182-190, 1993.

Öquist G., Chow W.S.: On the relationship between the quantum yield of photosystem II electron transport, as determined by chlorophyll fluorescence and the quantum yield of $\mathrm{CO}_{2}$-dependent $\mathrm{O}_{2}$ evolution. - Photosynth. Res. 33: 51-62, 1992.

Öquist G., Chow W.S., Anderson J.M.: Photoinhibition of photosynthesis represents a mechanism for the long-term regulation of photosystem II. - Planta 186: 450-460, 1992.

Ottander C., Campbell D., Öquist G.: Seasonal changes in photosystem II organisation and pigment composition in Pinus sylvestris. - Planta 197: 176-183, 1995.

Oukarroum A., El Madidi S., Schansker G., Strasser R.J.: Probing the responses of barley cultivars (Hordeum vulgare L.) by chlorophyll $a$ fluorescence OLKJIP under drought stress and re-watering. - Environ. Exp. Bot. 60: 438-446, 2007.

Oukarroum A., Strasser R.J., Schansker G.: Heat stress and the photosynthetic electron transport chain of the lichen Parmelina tiliacea (Hoffm.) Ach. in the dry and the wet state: Differences and similarities with the heat stress response of higher plants. - Photosynth. Res. 111: 303-314, 2012.

Papageorgiou G.C., Govindjee (ed.): Chlorophyll $a$ Fluorescence: A Signature of Photosynthesis. Pp. 818. Springer, Dordrecht 2004.

Peng L.W., Ma J.F., Chi W. et al.: LOW PSII ACCUMULATIONI is involved in efficient assembly of photosystem II in Arabidopsis thaliana. - Plant Cell 18: 955-969, 2006.

Peng Y., Lin A., Wang K. et al:: Global trends in DEM-related research from 1994 to 2013: A bibliometric analysis. Scientometrics 105: 347-366, 2015.

Pinnola A., Dall'Osto L., Gerotto C. et al:: Zeaxanthin binds to light-harvesting complex stress-related protein to enhance nonphotochemical quenching in Physcomitrella patens. Plant Cell 25: 3519-3534, 2013.

Rabinowitch E.I. : Photosynthesis and Related Processes. Vol. I: Chemistry of Photosynthesis, Chemosynthesis and Related Processes in Vitro and in Vivo. Pp. 599. Interscience, New York 1945.

Rabinowitch E.I.: Photosynthesis and Related Processes. Vol. II (Part 1): Spectroscopy and Fluorescence of Photosynthetic Pigments; Kinetics of Photosynthesis. Pp. 1-1208. Interscience, New York 1951.

Rabinowitch E.I.: Photosynthesis and Related Processes. Vol. II (Part 2): Kinetics of Photosynthesis (Continued); Addenda to Volume I and Volume II (Part 1). Pp. 1209-2088. Interscience, New York 1956.

Ruban A.V., Young A.J., Horton P.: Induction of nonphotochemical energy dissipation and absorbance changes in leaves: Evidence for changes in the state of the light-harvesting system of photosystem II in vivo. - Plant Physiol. 102: 741750, 1993.

Schansker G., Srivastava A., Govindjee, Strasser R.J.: Characterization of the $820-\mathrm{nm}$ transmission signal paralleling the chlorophyll $a$ fluorescence rise (OJIP) in pea leaves. - Funct. Plant Biol. 30: 785-796, 2003.

Scheer H.: Structure and Occurrence of Chlorophylls. Pp. 28. CRC Press, Boca Raton 1991.

Sherameti I., Tripathi S., Varma A., Oelmüller R.: The rootcolonizing endophyte Pirifomospora indica confers drought 
tolerance in Arabidopsis by stimulating the expression of drought stress-related genes in leaves. - Mol. Plant Microbe In. 21: 799-807, 2008.

Singsass E.L., Lerdau M., Winter K., Sharkey T.D.: Isoprene increases thermotolerance of isoprene-emitting species. Plant Physiol. 115: 1413-1420, 1997.

Small H.: Co-citation in the scientific literature: A new measure of the relationship between two documents. - J. Am. Soc. Inform. Sci. 24: 265-269, 1973.

Stirbet A., Govindjee: On the relation between the Kautsky effect (chlorophyll $a$ fluorescence induction) and Photosystem II: Basics and applications of the OJIP fluorescence transient. J. Photoch. Photobio. B 104: 236-257, 2011.

Strasser R.J., Tsimilli-Michael M., Qiang S., Goltsev V.: Simultaneous in vivo recording of prompt and delayed fluorescence and 820-nm reflection changes during drying and after rehydration of the resurrection plant Haberlea rhodopensis. - BBA-Bioenergetics 1797: 1313-1326, 2010.

Strauss A.J., Krüger G.H.J., Strasser R.J., Van Heerden P.D.R.: Ranking of dark chilling tolerance in soybean genotypes probed by the chlorophyll $a$ fluorescence transient O-J-I-P. Environ. Exp. Bot. 56: 147-157, 2006.

Streb P., Josse E.-M., Gallouët E. et al.: Evidence for alternative electron sinks to photosynthetic carbon assimilation in the high mountain plant species Ranunculus glacialis. - Plant Cell. Environ. 28: 1123-1135, 2005.

Streb P., Shang W., Feierabend J., Bligny R.: Divergent strategies of photoprotection in high-mountain plants. - Planta 207: 313-324, 1998.

Valentini R., Epron D., Angelis P.D. et al.: In situ estimation of net $\mathrm{CO}_{2}$ assimilation, photosynthetic electron flow and photorespiration in Turkey oak (Q. cerris L.) leaves: Diurnal cycles under different levels of water supply. - Plant Cell. Environ. 18: 631-640, 1995.

van Eck N.J., Waltman L.: Software survey: VOSviewer, a computer program for bibliometric mapping. - Scientometrics 84: 523-538, 2010.

van Kooten O., Snel J.F.H.: The use of chlorophyll fluorescence nomenclature in plant stress physiology. - Photosynth. Res. 25: 147-150, 1990.

Verhoeven A.S., Adams W.W., Demmig-Adams B.: Two forms of sustained xanthophyll cycle-dependent energy dissipation in overwintering Euonymus kiautschovicus. - Plant Cell. Environ. 21: 893-903, 1998.

Watts D.J., Strogatz S.H.: Collective dynamics of 'small-world' networks. - Nature 393: 440-442, 1998.

Zhu N., Liu X., Liu Z. et al:: Deep learning for smart agriculture: Concepts, tools, applications, and opportunities. - Int. J. Agr. Biol. Eng. 11: 32-44, 2018.

Zhu X.G., Govindjee, Baker N.R. et al.: Chlorophyll a fluorescence induction kinetics in leaves predicted from a model describing each discrete step of excitation energy and electron transfer associated with Photosystem II. - Planta 223: 114$133,2005$.

Živčák M., Brestič M., Kalaji H.M., Govindjee: Photosynthetic responses of sun- and shade-grown barley leaves to high light: Is the lower PSII connectivity in shade leaves associated with protection against excess of light? - Photosynth. Res. 119: 339-354, 2014.

(C) The authors. This is an open access article distributed under the terms of the Creative Commons BY-NC-ND Licence. 